\title{
Linking instantaneous rate of injection to x-ray needle lift measurements for a direct-acting piezoelectric injector
}

\author{
Juan P. Viera ${ }^{\mathrm{a}, *}$, Raul Payri ${ }^{\mathrm{a}}$, Andrew B. Swantek ${ }^{\mathrm{b}}$, Daniel J. Duke ${ }^{\mathrm{b}}$, \\ Nicolas Sovis ${ }^{\mathrm{b}}$, Alan L. Kastengren ${ }^{\mathrm{c}}$, Christopher F. Powell ${ }^{\mathrm{b}}$ \\ ${ }^{a}$ CMT-Motores Térmicos, Universitat Politècnica de València, Camino de Vera s/n, \\ 46022 Valencia, Spain \\ ${ }^{b}$ Argonne National Laboratory, Energy Systems Division, Argonne, IL 60439 USA \\ ${ }^{c}$ Argonne National Laboratory, Advanced Photon Source, X-ray Science Division, \\ Argonne, IL 60439 USA
}

\begin{abstract}
Internal combustion engines have been and still are key players in today's world. Ever increasing fuel consumption standards and the ongoing concerns about exhaust emissions have pushed the industry to research new concepts and develop new technologies that address these challenges. To this end, the diesel direct injection system has recently seen the introduction of directacting piezoelectric injectors, which provide engineers with direct control over the needle lift, and thus instantaneous rate of injection (ROI). Even though this type of injector has been studied previously, no direct link between the instantaneous needle lift and the resulting rate of injection has been quantified. This study presents an experimental analysis of the relationship between instantaneous partial needle lifts and the corresponding ROI. A prototype direct-acting injector was utilized to produce steady injections of different magnitude by partially lifting the needle. The ROI measurements were carried out at CMT-Motores Térmicos utilizing a standard injection rate discharge curve indicator based on the Bosch method (anechoic tube). The needle lift measurements were performed at the Advanced Photon Source at Argonne National Laboratory. The analysis seeks both to contribute to the current understanding of the influence that partial needle lifts have over
\end{abstract}

\footnotetext{
*Corresponding author

Email address: juavieso@mot.upv.es (Juan P. Viera)
}

Preprint submitted to Energy Conversion and Management

January 14, 2016

(C) 2016. This manuscript version is made available under the Elsevier user license

http:/www.elsevier.com/open-access/userlicense/1.0/ 
the instantaneous ROI and to provide experimental data with parametric variations useful for numerical model validations. Results show a strong relationship between the steady partial needle lift and the ROI. The effect is non-linear, and also strongly dependent on the injection pressure. The steady lift value at which the needle ceases to influence the ROI increases with the injection pressure. Finally, a transient analysis is presented, showing that the needle velocity may considerably affect the instantaneous ROI, because of the volume displaced inside the nozzle. Results presented in this study show that at constant injection pressure and energizing time, this injector has the potential to control many aspects of the ROI and thus, the heat release rate. Also, data presented are useful for numerical model validations, which would provide detailed insight into the physical processes that drive these observations, and potentially, to the effects of these features on combustion performance.

Keywords:

Diesel direct injection, rate of injection, synchrotron, x-ray imaging, needle lift.

\section{Introduction}

Internal combustion engines have played a significant part in shaping the 
injected mass is a function of both injection pressure and energizing time (ET). To a certain extent, this limits combustion control, since the ET also determines heat release phasing and rates [5-7]. The recent introduction of direct-acting piezoelectric injectors [8] provides engineers with direct control over the needle lift - thus, over the instantaneous fuel flow - which opens a wide range of possibilities for controlling the injection event and combustion process [9-11].

Interest in understanding injector and spray behavior under partial needle lift conditions is not bound exclusively to direct-acting injectors, since conventional injectors also operate under these conditions in various situations (i.e., pilot injections and the start or end of injections). Chiavola and Palmieri [12] utilized a numerical computational fluid dynamics (CFD) model to study the effect of needle radial motion (needle wobble) on cavitation and flow patterns within a valve covered orifice nozzle, showing that the radial needle location (and speed) can greatly affect the hole-to-hole symmetry of the flow. Later, Som et al. [13] presented numerical results of the effects of needle lift over in-nozzle flow, showing that needle lift significantly affects the velocity fields through the needle seat, the nozzle sac, and the orifice. Ferrari and Mittica [14] presented a finite element model of a direct-acting piezoelectric injector that included electrical, mechanical, and hydraulic submodels, concluding that the injection pressure strongly affects the behavior of the direct-acting mechanism. Payri et al. [15-17] employed a prototype directacting injector to study the effect of steady partial needle lift on nozzle flow characteristics and macroscopic spray development. Their studies showed a strong relationship between fuel mass flow rates through the nozzle and estimated needle lift, also finding that needle lift and piezo actuator response are strongly affected by the injection pressure. Moreover, a strong correlation between the liquid length, vapor spray penetration rate, and needle lift was evidenced. Recently, Desantes et al. [18] employed a numerical CFD model to study the relationship between needle lift and ROI for a micro-sac multi-hole nozzle with cylindrical orifices. In their study, the authors show that the onset of the cavitation void occurs at the needle seat for low needle lift conditions, and moves downstream to the orifice when needle lift is high enough.

It is important to point out that actual needle lifts in the studies presented by Payri et al. [15-17] are unknown and were not directly controlled, so existing studies do not establish a direct link between needle lift values and spray formation response, for example, to validate CFD models. 
Measuring instantaneous needle lift of diesel injectors under realistic operating conditions presents a considerable challenge. X-ray imaging is advantageous for this particular application, as the rays are able to penetrate the steel nozzle wall, eliminating the need for any modification of the injector. Synchrotron x-rays provide detailed measurements of the internal geometry of fuel injectors by exploiting the phase contrast that occurs when highly collimated x-rays are weakly diffracted by the phase boundaries at the nozzle walls [19]. Owing to the high flux of the synchrotron source, time-resolved measurements of the internal needle motion can be made with microscale precision using a high-speed camera [20]. These measurements have been coupled with observations of cavitation and gas ingestion inside the injector and changes in the external flow [21-23].

This paper presents an experimental analysis of the relationship between instantaneous partial needle lifts and ROI. A prototype direct-acting injector is utilized to produce steady injections of different magnitude by partially lifting the needle. Also, transient features such as ramp rates and injection rate shaping are explored. The ROI measurements were carried out at CMTMotores Térmicos (CMT) utilizing a standard injection rate discharge curve indicator (IRDCI) based in the Bosch method [24]. The needle lift measurements were performed at the Advanced Photon Source (APS) located at Argonne National Laboratory. The analysis pursues two different goals: first, to contribute to the understanding of the influence that partial needle lifts have over the instantaneous ROI; second, to provide extensive experimental data with parametric variations useful for numerical model validations, which could potentially be later employed to enhance the current understanding of partial needle lift and injection rate shaping over global combustion performance.

\section{Materials and methods}

\subsection{Rate of injection measurements}

The ROI measurements were carried out utilizing a commercial Injection Discharge Rate Curve Indicator (IRDCI)[24], which consists of injecting fuel into a fuel-filled long tube. The instantaneous ROI is proportional to the pressure signal measured by a piezoelectric pressure sensor [25]. For these experiments, a total of 50 injections were acquired at each test condition. Details of the full apparatus and technique can be found in the work of Payri et al. [25, 26]. Injection pressure was measured at the common rail. 


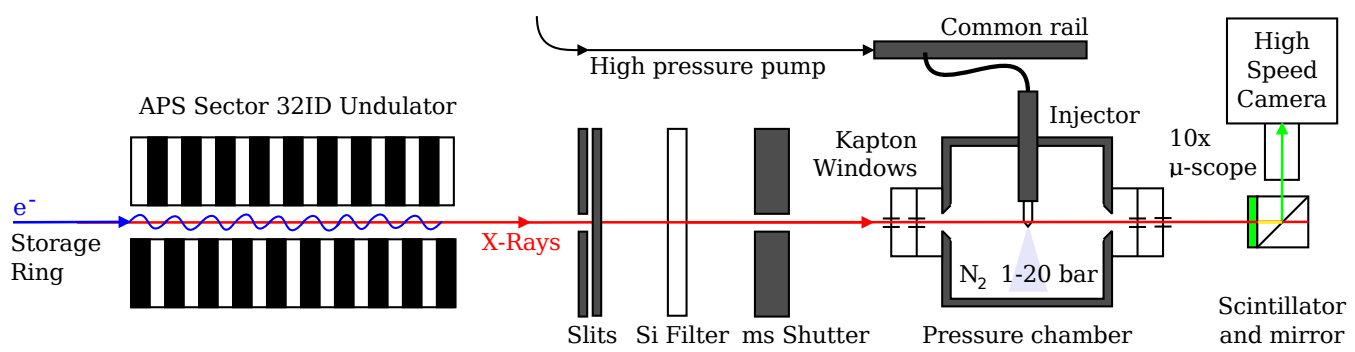

Figure 1: Schematic diagram of x-ray phase-contrast imaging experiment at the 32-ID beamline of the Advanced Photon Source at Argonne National Laboratory (not to scale).

Note that the final repetition-averaged ROI signal for a given test condition is scaled/corrected with the total injected mass, which is simultaneously measured by a precision electronic scale [25]. The fuel utilized for the ROI experiments was ISO 4113 calibration fluid. Details of the test conditions covered are presented in Table 1.

Table 1: Rate of injection experiments test plan

\begin{tabular}{lcccccc}
\hline Parameter & \multicolumn{7}{c}{ Test conditions } \\
\hline Inj. press. [bar] & 500 & 500 & 1500 & 1500 & 500 & 500 \\
Back press. [bar] & $50 ; 11$ & 50 & $50 ; 11$ & 50 & 50 & 50 \\
Control volt. [V] & $135 ; 120 ; 105 ; 90 ; 85$ & $150 ; 132 ; 126$ & 150,$118 ; 116$ & $85 \rightarrow 120$ & $95 \rightarrow 120$ \\
& $100 ; 95$ & 1 & 1 & 114 & & \\
Ramp rate [V/us] & 1 & 1 & 2 & 2 & 2 \\
Injection shape & square & square & square & square & boot & boot \\
\hline
\end{tabular}

\subsection{Phase-contrast imaging}

X-ray measurements of needle displacement were performed at the 32-ID beamline of the Advanced Photon Source at Argonne National Laboratory [27]. The experiment setup is shown in Figure 1, and the test conditions covered are presented in Table 2. A common-rail diesel injection system powered by an electrically driven mechanical pump delivered fuel to the injector. Injection pressure was measured at the common rail. The fuel was sprayed into a chamber pressurized with $\mathrm{N}_{2}$. Kapton windows allowed the $\mathrm{x}$-rays to pass through the chamber with minimum absorption. The experiments were conducted at room temperature. The fuel used was a commercial 
diesel surrogate with approximately $2 \%$ (by mass) cerium additive. The fuel had a density of $865.6 \mathrm{~kg} / \mathrm{m}^{3}$ and a viscosity of $3.22 \mathrm{cSt}$ at $25^{\circ} \mathrm{C}$. For these experiments, a total of 21 injections were acquired for each test condition.

The peak irradiance of the x-ray beam was approximately $3 \times 10^{12} \mathrm{ph} / \mathrm{s} / \mathrm{mm}^{2} / 0.1 \% \mathrm{BW}$ with an undulator gap of $17 \mathrm{~mm}$. The distance from the source to the experiment was approximately $35.5 \mathrm{~m}$. A $5 \mathrm{~mm}$ Si filter was used to remove low-energy photons from the raw x-ray source. A $150 \mu \mathrm{m}$ LuAG:Ce scintillator [28] converted the x-rays to visible light, which was recorded by a Photron SA-Z high-speed camera at $150 \mathrm{kHz}$ frame rate and $566 \mathrm{~ns}$ exposure time, fitted with a $10 \times$ long-distance microscope. The propagation distance from the experiment to the scintillator was approximately $600 \mathrm{~mm}$. The spatial resolution achieved with this system was $1.95 \mu \mathrm{m}$ per pixel.

Table 2: Phase-contrast imaging experiments test plan

\begin{tabular}{lccc}
\hline Parameter & \multicolumn{3}{c}{ Test conditions } \\
\hline Inj. press. [bar] & 500 & 500 & 1500 \\
Back press. [bar] & 1 & $1 ; 11$ & 1 \\
Control volt. [V] & $135 ; 105 ; 100$ & $120 ; 85$ & $150 ; 132 ; 126$ \\
& $95 ; 90 ; 80$ & & 118 \\
Ramp rate [V/us] & 1 & 1 & 1 \\
Injection shape & square & square & square \\
\hline
\end{tabular}

Note that there is not complete overlap between the ROI and phasecontrast imaging test plans. Since the time window available for both experiments was limited, only a select group of test conditions overlap between them, and the rest comprise particular tests of interest for each of the variables being measured.

\subsection{The direct-acting prototype injector}

Figure 2 shows a sample image of the nozzle. The figure depicts how the needle tip and seat geometries are quite different from conventional sac designs, where the needle tip occupies less of the sac volume, and the seat angles are smaller [20]. During and injection event, the needle lifts towards the upper-left corner of the image, allowing fuel to flow through the needle seat and towards the outlet orifices.

The direct-acting mechanisms consist of a rocker or lever system that connects the needle to the piezo-stack linear actuator, similar to the mechanism detailed by Ferrari and Mittica [14]. The needle rests in zero-lift position 


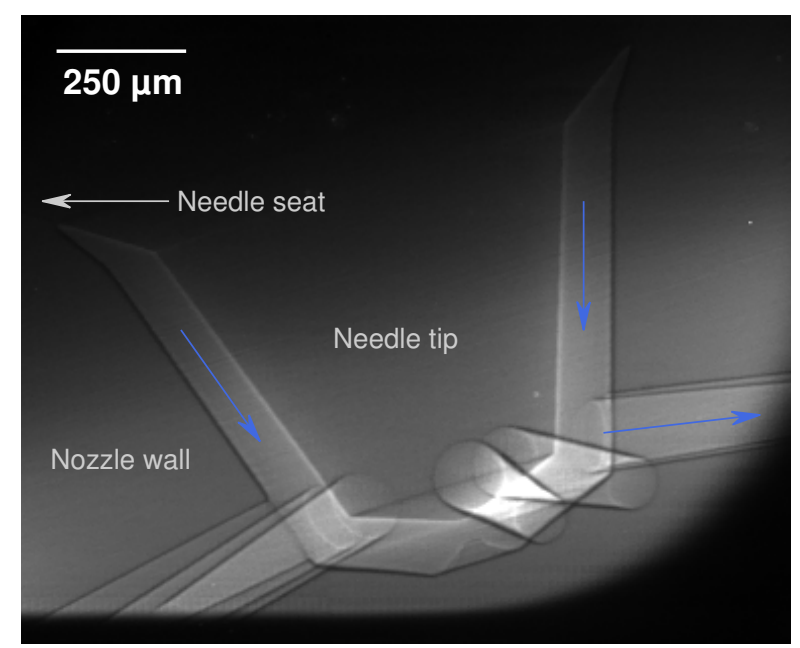

Figure 2: Raw image of the nozzle obtained from x-ray phase contrast imaging. Note that there is no lift in this figure and the needle is resting on the seat, which is at the upper left and right corners of the image. Fuel flows from the needle seat towards the outlet orifices as indicated by the blue arrows.

when the piezo-stack is not charged because injection pressure and a mechanical spring push it against its seat.

Needle lift is controlled through the voltage applied to the piezo-stack linear actuator. Figure 3 shows an example of a set of various control signals utilized to produce injections with different needle lifts. For all results presented in this paper, the ET was kept constant at $3.2 \mathrm{~ms}$, which was purposely set to obtain long ROI and needle lift signals with both transient and steady state stages. Note that Figure 3 shows time values measured after the start of energizing (SOE), which is convenient for control signals. For measurements of spray characteristics, time values are often referenced to the start of injection (SOI), which is usually several hundred microseconds after the SOE.

Each control signal steady voltage level shown in Figure 3 is reached at a rising ramp rate of $1 \mathrm{~V} / \mathrm{us}$. Even though the steady voltage level determines the steady needle lift behavior, transient needle displacements are strongly affected by the slope of the control signal. Control signal de-energizing ramp rates were kept constant at $1 \mathrm{~V} / \mu$ s through all experiments presented in this paper. 


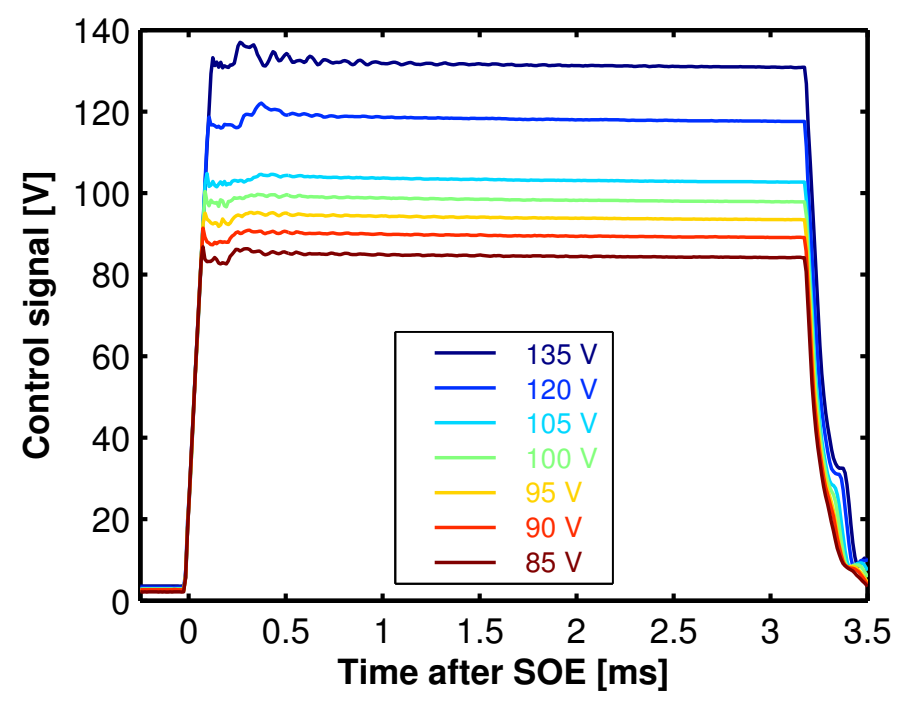

Figure 3: Injector control signals of different amplitude but equal energizing time of $3.2 \mathrm{~ms}$ and rising ramp rate of $1 \mathrm{~V} / \mathrm{us}$.

\section{Results and discussion}

\subsection{Rate of injection measurements}

Figure 4 illustrates how partial needle lifts are able to throttle the instantaneous ROI down to very low rates, even though the pressure drop along the nozzle remains constant for all cases shown. In particular, these ROI signals correspond to the control signals presented in Figure 3. These results are similar to the observations of Payri et al. [15], but in this case, ROI throttling could be taken to a lower limit because direct control of the signal was possible, instead of utilizing a modified electronic control unit. In these high throttling situations, an initial overshoot of the steady injection rate is observed, even though all cases have control signals with equal ramp rates of $1 \mathrm{~V} /$ us. It is possible to suppress this overshoot by tuning the control signal appropriately to the response frequency of the system, however, this was not the objective of these experiments as the overshoot shows interesting features in the transient response of the system. Moreover, it is important to note that ROI response is of second order, with moderate damping, which is related to (but not directly linked to) the expected second order response for a piezo-actuated damped system with inertia. On the other hand, all injection rates show a high frequency component, especially strong for the $135 \mathrm{~V}$ case. 


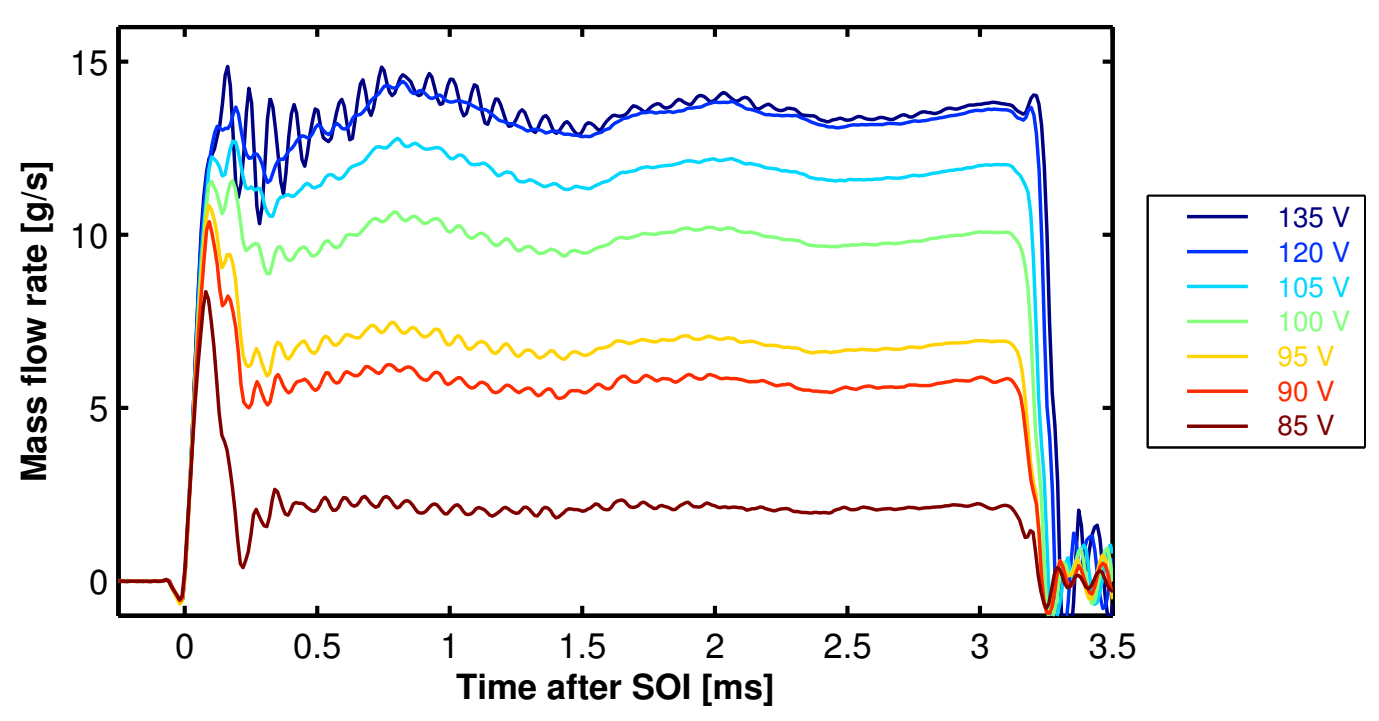

Figure 4: Instantaneous ROI for different drive signal voltages at an injection pressure of 500 bar and a back pressure of 50 bar. The ramp rate of the control signal for all the differente voltages is $1 \mathrm{~V} / \mathrm{us}$.

These are pressures waves initiated when the needle suddenly stops lifting, which are artifacts of the fuel-filled injection discharge tube and are not to be mistaken for ROI fluctuations actually caused by needle vibration.

The injection pressure, which pushes to close the needle, strongly affects the span of effective throttling at higher injection pressures, as Figure 5 illustrates. In this case, the $132 \mathrm{~V}$ ROI signal features a slower ramp when compared to the full lift $(150 \mathrm{~V})$ case, even though both cases have control signals with equal ramp rates of $1 \mathrm{~V} / \mathrm{us}$. Also, it is important to point out that steady signal voltages between $131 \mathrm{~V}$ to $127 \mathrm{~V}$ produced very unsteady behaviors, where each single injection could produce signals that would fall between the $132 \mathrm{~V}$ and $126 \mathrm{~V}$ signals. This is believed to occur because deformations in the rocker mechanism - which counteracts the force produced by the injection pressure - widen the pivot point and reduce the mechanical advantage [14], deteriorating the rocker pivoting action. Therefore, at high injection pressures, more energy is necessary to overcome the increased force imparted by the higher pressure and the distorted pivot. Control signals with ramps of $1 \mathrm{~V} / \mu$ s and steady signal voltages below $126 \mathrm{~V}$ did not give the piezo-stack enough energy to keep the needle lifted after the initial overshoot, which made the injections behave similar to pilot injections of very short 


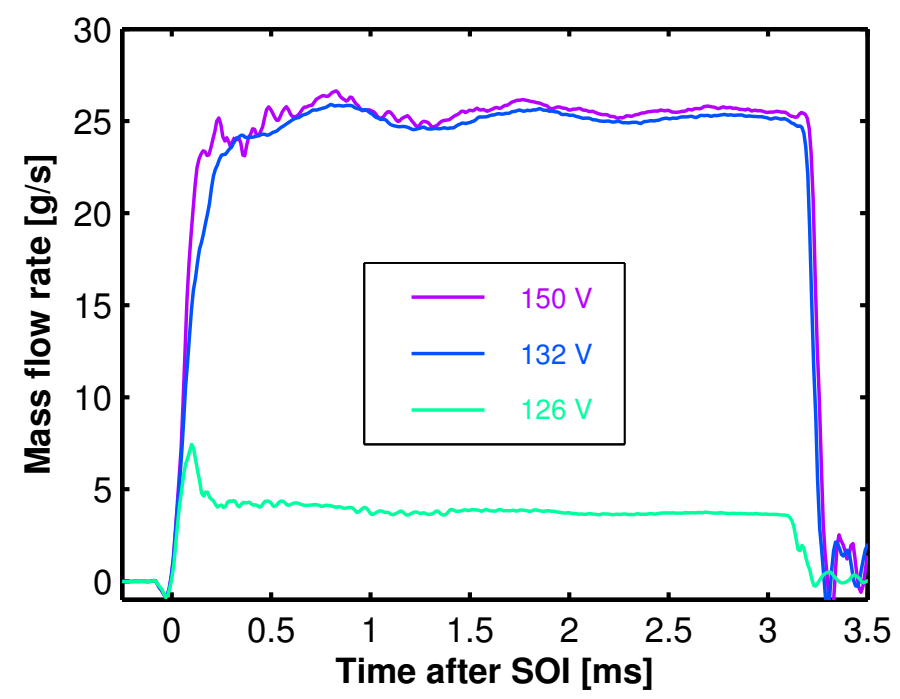

Figure 5: Instantaneous ROI for different drive signal voltages at an injection pressure of 1500 bar and a back pressure of 50 bar. The ramp rate of the control signal for all the differente voltages is $1 \mathrm{~V} / \mathrm{\mu s}$.

effective ET.

A faster ramp in the control signal would energize the piezo-stack actuator more rapidly, which can help overcome the force produced by the injection pressure at the beginning of the injection event. Figure 6 illustrates how changing the ramp rate from $1 \mathrm{~V} / \mu \mathrm{s}$ to $2 \mathrm{~V} / \mu$ s aids lifting the needle in high injection pressure scenarios. This enables the possibility of applying control signals with lower steady voltages, enhancing the ROI throttling span at this injection pressure. As expected, for this faster ramp rate there is still a range of steady voltages that produce inconsistent injections. Finally, looking at the $114 \mathrm{~V}$ signal, the high frequency vibration at the latter part of the injection event is a pressure wave oscillation because of the fuel-filled IRDCI, not to be mistaken for a real fluctuation in the ROI caused by needle lift behavior.

Taking the steady, time-averaged ROI value of each signal facilitates the analysis of the control signal steady voltage effects over the ROI. Figure 7 illustrates the global effect of the control signal steady voltage over the ROI and thus, the discharge coefficient. For injection pressures of 500 bar the wide span of steady ROIs possible is evident. As expected, the span width decreases as injection pressure increases. Also as depicted by Figures 5 and 6 , the span of throttling ability can be stretched by properly preparing the 


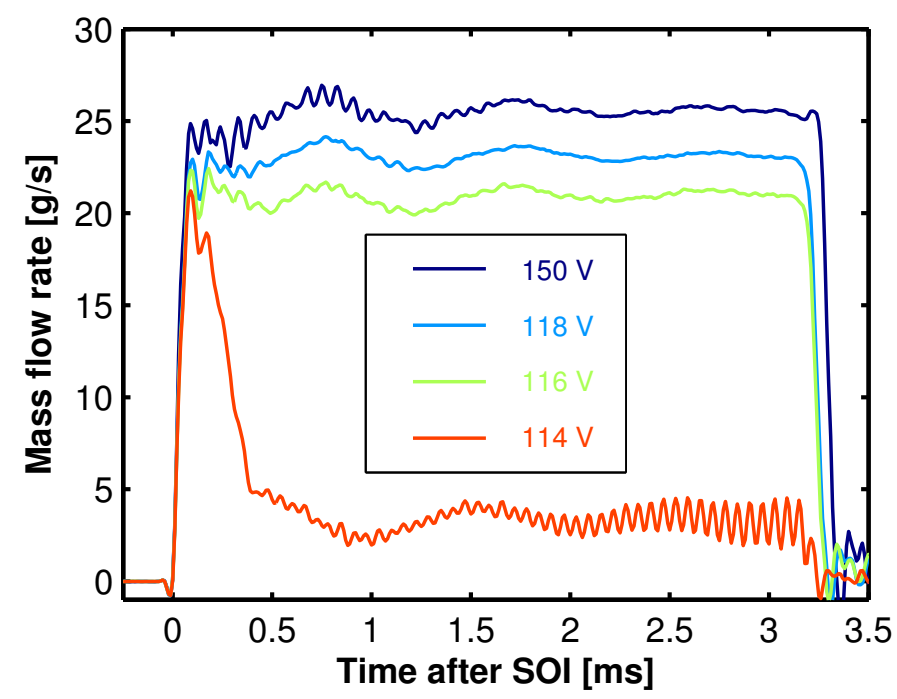

Figure 6: Instantaneous ROI for different drive signal voltages at an injection pressure of 1500 bar and a back pressure of 50 bar. The ramp rate of the control signal for all the different voltages is $2 \mathrm{~V} /$ us.

control signal (in this study, just the rising ramp rate effect is presented). The discharge coefficient of the complete nozzle (Figure 7-bottom) also shows how the needle lift is able to throttle the ROI, lowering the discharge coefficients from 0.81 to as low as 0.11 . Note that discharge coefficients converge to a maximum value as full lift is reached. Finally, it is important to point out that the effect of the voltage over the ROI is not linear.

The direct-acting feature of the injector enables control not only of partial needle lift but also of ROI profiling [17]. In addition to the reference case - a full lift 'square' shaped injection at a rail pressure of 500 bar and a back pressure of 50 bar - two 'boot' shaped profiles were tested for comparison. The 'boot' profile is produced by introducing a step in the control signal, as depicted in Figure 8. Note that even though the 'square' shaped injection is produced by a control signal with a higher steady voltage in the first stage of the injection event, the ROI of the 'boot2' shaped injection overshoots past it, due to the faster control signal ramp rate. On the same lines, these rapid needle movements and stops produce the pressure waves that are observed as higher frequency fluctuations in the ROI signals. 

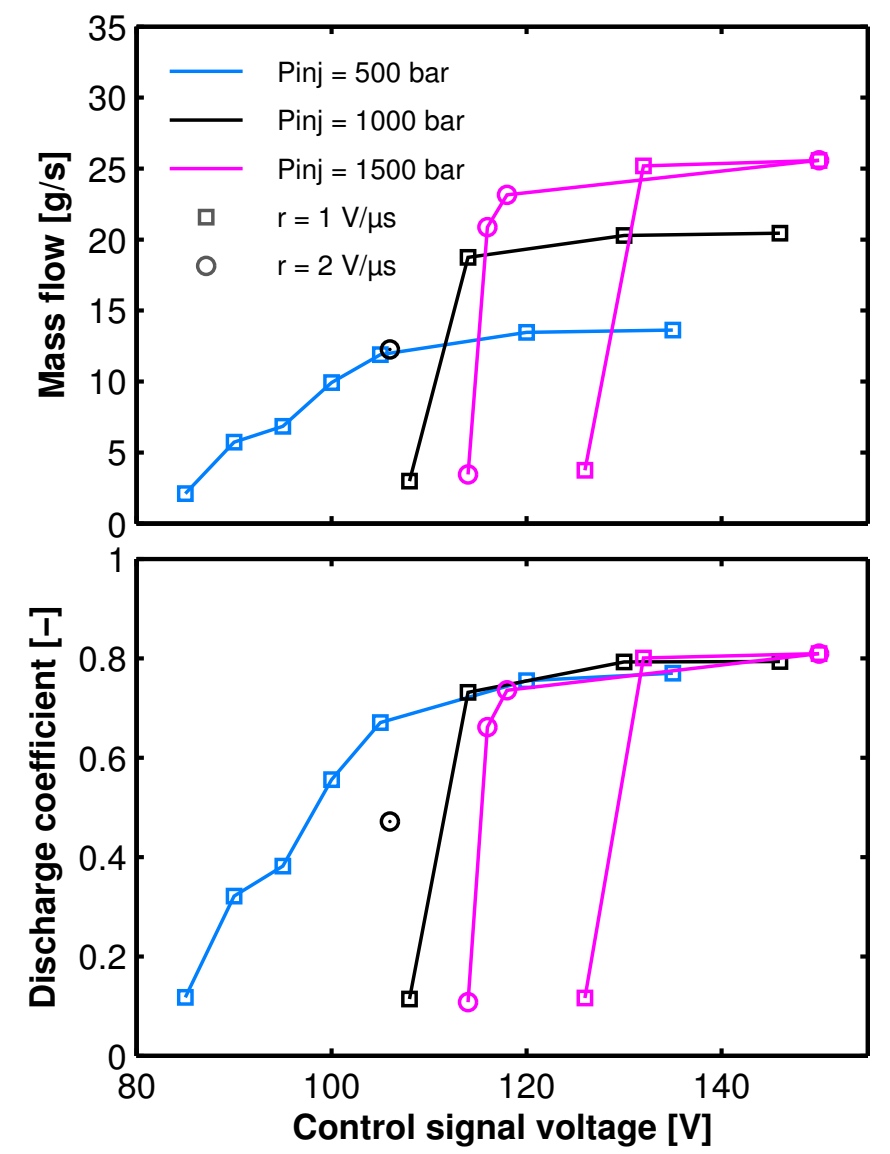

Figure 7: Time-averaged steady ROI response to the control signal steady voltage at three different injection pressures and two control signal ramp rates. Note that injection pressures are indicated by different colors, while control signal ramp rates are indicated by different symbols. In this case, ambient pressure is constant at 50 bar. 

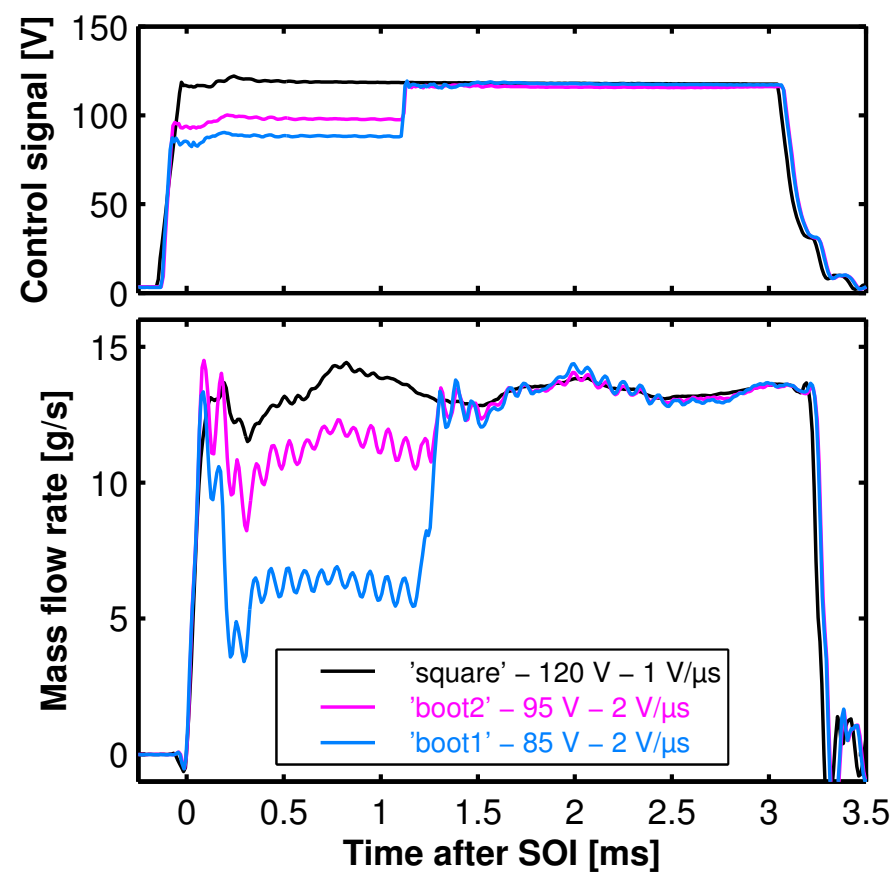

Figure 8: Comparison of three different injection rate shapes at an injection pressure of 500 bar and a back pressure of 50 bar. The voltage levels indicated in the figure legend correspond to the voltages of the first step of the control signal - constant for the 'square' shaped injection. Note that after this first step, all voltages equalize at $120 \mathrm{~V}$. 


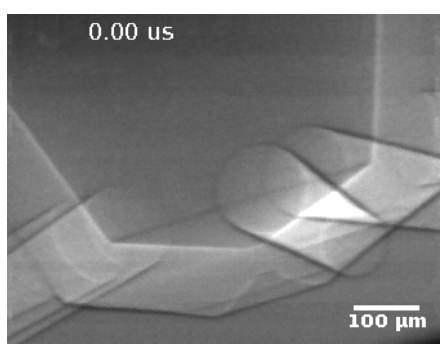

(a) Needle fully closed

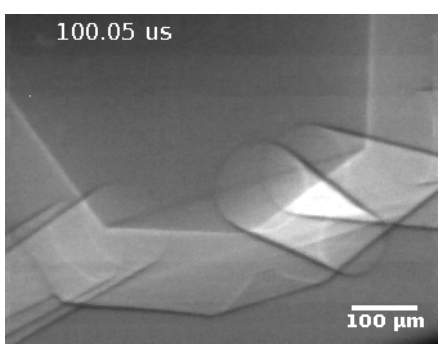

(b) Needle opening

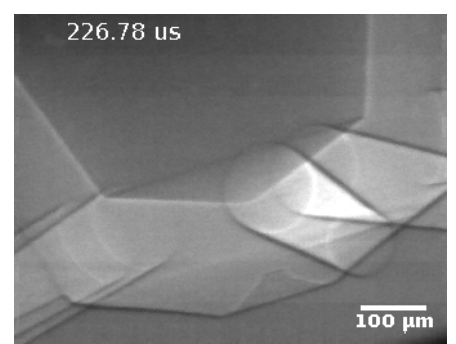

(c) Needle fully open

Figure 9: Sequence of x-ray images of needle lift for a single test at an injection pressure of 1500 bar, back pressure of 1 bar, with a control signal ramp rate of $1 \mathrm{~V} / \mu \mathrm{s}$ and a steady voltage of $150 \mathrm{~V}$.

\subsection{Needle displacement}

X-ray phase-contrast images were used for time-resolved tracking of needle displacement. The tracking algorithm consists of a simple 2D crosscorrelation routine that evaluates the cross-correlation between an interrogation sector of the first images (before any needle displacement) to the subsequent images [20-22]. Figure 9 is a typical sequence of raw images that permit observation of needle displacement.

As shown in Figure 10, needle motion in the seat region was also imaged for particular test conditions. Note the angle between the needle and seat surfaces, which promotes a positive seal when the needle is fully closed. These images were obtained at the reference, full lift condition: an injection pressure of 500 bar, control signal ramp rate of $1 \mathrm{~V} / \mathrm{\mu s}$ and steady voltage level of $120 \mathrm{~V}$.

Due to the limited time available for measurements, only a select group of test conditions could be imaged. Thus, the experiments focused on measurements that could enhance the current understanding of the link between needle lift and ROI. Figure 11 depicts needle lifts measured at the different drive voltage levels. This figure explains the results observed for the ROI in Figure 4 at comparable test conditions: the injector is able to successfully and consistently throttle the ROI by partially lifting the needle. Note that the overshoots in the transients of the ROI curves in Figure 4 are also present in the needle lifts shown in Figure 11, as is the second order response, which again underscores the direct link between instantaneous needle lift and ROI. Needle lift measurements at higher injection pressure, illustrated in Figure 


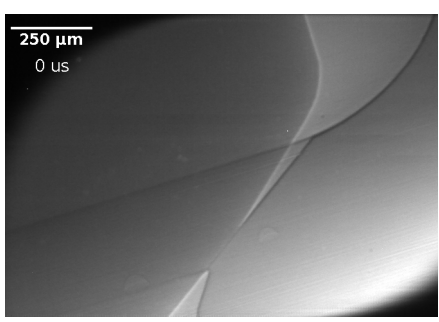

(a) Needle fully closed

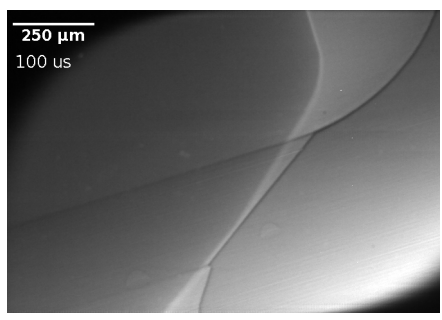

(b) Needle opening

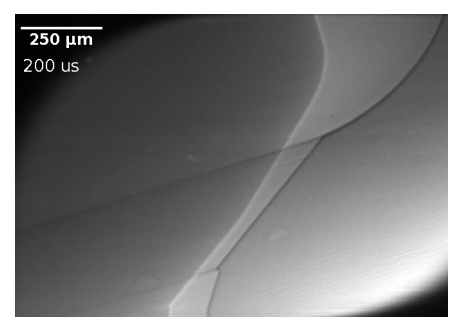

(c) Needle fully open

Figure 10: Sequence of x-ray images of the needle seat region. The test was performed at an injection pressure of 500 bar and a back pressure of 1 bar, with a control signal ramp rate of $1 \mathrm{~V} / \mu \mathrm{s}$ and a steady voltage level of $120 \mathrm{~V}$. Fuel flows from top to bottom in these images.

12, also correlate well to the ROI observations of Figure 5. Note the considerably slower lift velocity for the $132 \mathrm{~V}$ signal, which clearly explains the slower slope in the mass flow rate previously observed for the same voltage case.

The effect of small back pressure differences was evaluated by comparing two back pressure cases at the two limits of needle lift. Figure 13 illustrates the comparison, showing that 10 bar of back pressure difference has no significant effect on the needle lift, confirming that the rest of the lift measurements would represent the real lifts during the ROI experiments performed at a back pressure of 11 bar. This was important to assess, especially for the low lift critical cases where a further increase in back pressure could impact the lift.

As previously done with the ROI, taking time-averaged values in the steady parts of the signals allows for easier observation of the link between steady needle lift and control signal voltage. Figure 14 illustrates that, unlike the case of ROIs, the relationship between the steady needle lift and the control signal voltage is quite linear. Note that in some cases, several measurements are shown at the same control signal voltage level, because the plot includes back pressure variations. The two outliers at injection pressures of 1500 bar that do not follow the linear trend correspond to those cases where the needle is not lifted properly due to deformations in the rocker mechanism, which was also seen in the ROI results. Payri et al. [15] reached similar conclusions through numerical analysis of the flow inside the nozzle, estimating the necessary needle lifts to produce the mass flow rates measured at each 


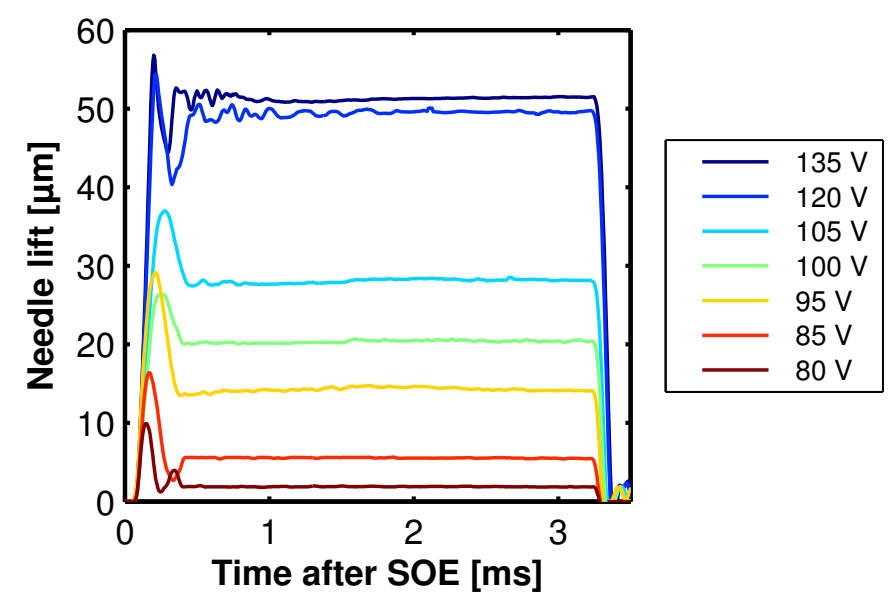

Figure 11: Instantaneous needle lift for different drive signal voltages at an injection pressure of 500 bar and a back pressure of 1 bar. The ramp rate of the control signal for all the differente voltages is $1 \mathrm{~V} / \mathrm{\mu s}$.

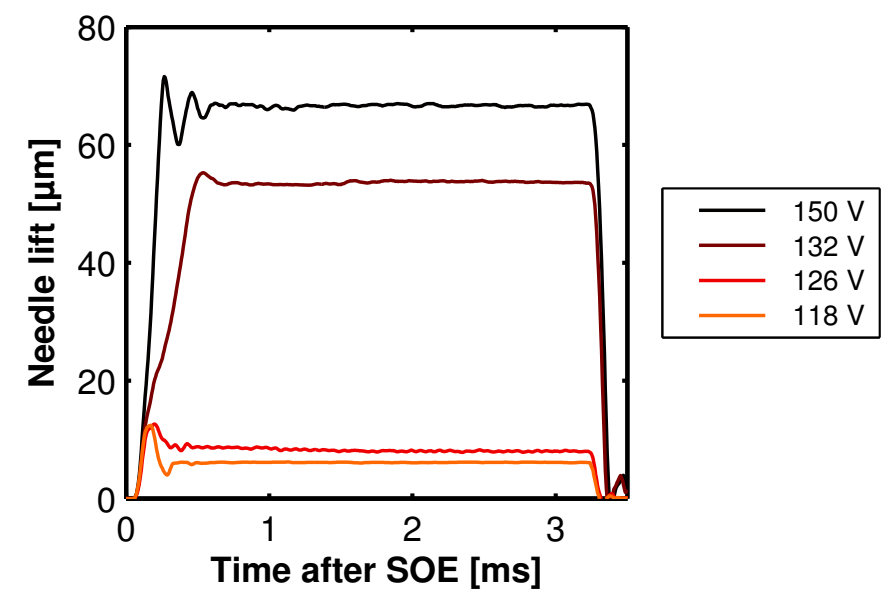

Figure 12: Instantaneous needle lift for different drive signal voltages at an injection pressure of 1500 bar and a back pressure of 1 bar. The ramp rate of the control signal for all the differente voltages is $1 \mathrm{~V} / \mathrm{\mu s}$. 


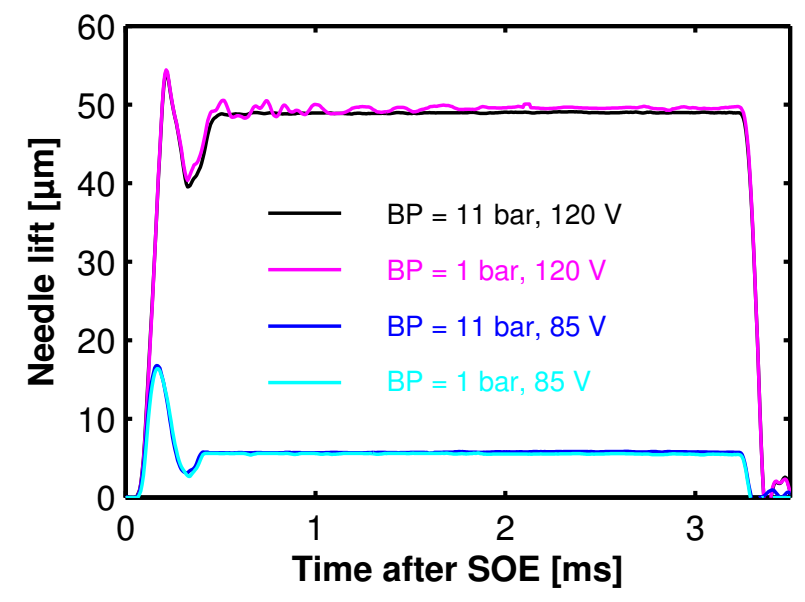

Figure 13: Evaluation of the effect of small increase in back pressure over the instantaneous needle lift. All tests where performed at an injection pressure of 500 bar. The ramp rate of the control signal for all cases is $1 \mathrm{~V} / \mu \mathrm{s}$.

piezo charge. The results presented here confirm and quantify the estimates of Payri et al. [15].

\subsection{Instantaneous relationship between the rate of injection and needle lift}

In this section the instantaneous relationship between the rate of injection and needle lift is evaluated. Note that the correlation between these variables is done for the repetition-average time-resolved responses of each variable, where the ROI experiments comprise a total of 50 injections while the needle lift experiments comprise 21 injections. This difference, however, is not expected to affect the results presented since shot-to-shot dispersion of either measurement is remarkably low, approximately $3 \%$ for lift measurements and $4 \%$ for ROI measurements.

Note that only the ROIs measured at a back pressure of 11 bar are considered, to guarantee that the needle lifts measured are relevant to the corresponding ROI at similar test conditions. Unfortunately, it was not possible to perform the same number of ROI experiments at a back pressure of 11 bar as were performed for 50 bar. Therefore, this section correlates only the test conditions that were available in both ROI and needle lift measurements. Note also that ROIs were sampled at $100 \mathrm{kHz}$ while $\mathrm{x}$-ray phase contrast images were acquired at $150 \mathrm{kHz}$. In order to make it possible to establish an instantaneous link between the two responses, the needle lift signals were 


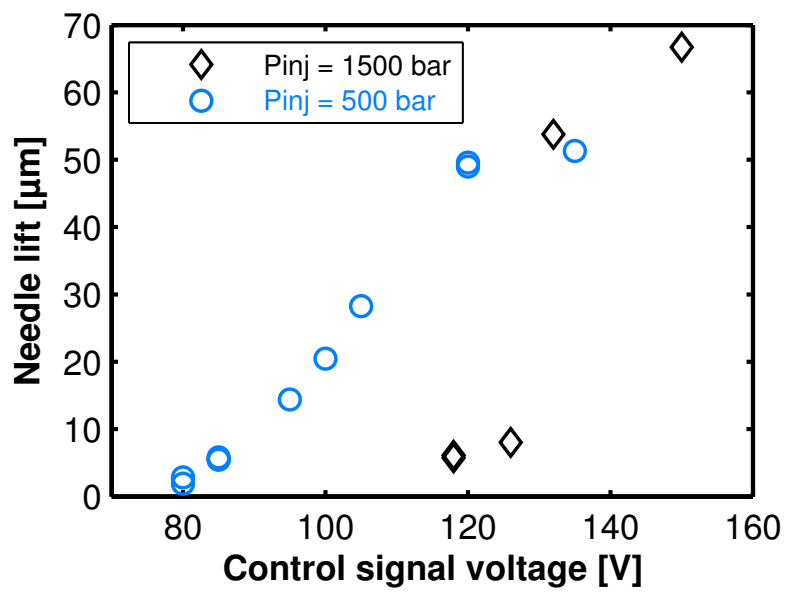

Figure 14: Time-averaged steady needle lift response to the control signal steady voltage at the two injection pressures tested.

down-sampled to the time domain of the ROI signals.

Figure 15 illustrates the ROI as a function of instantaneous needle lifts. Injection pressures are separated into two sub-figures for clarity. The "clouds" of points represent steady state ROI and lift conditions (including points before and after the injection event, which comprise the cloud near the origin), while the transients are represented by the points going from zero up to their corresponding steady state cloud. Note that the complete injection event goes anti-clockwise in this figure, as indicated by the light-gray arrows. Therefore, for each voltage, the injection event starts at the origin, travels through the bottom-right corner of the plot up to the corresponding steady state lift-ROI combination, and finally returns to zero through the top-left corner of the plot.

The steaty state shows an asymptotic behavior, where increasing needle lift after a certain point (the "full lift" definition) has no effect on the steady ROI. As observed in the ROI results, the "full lift" height depends on the injection pressure: at a rail pressure of 500 bar, the needle lift ceases to have an effect over the ROI near $50 \mu \mathrm{m}$, while at 1500 bar this condition is reached near $70 \mu \mathrm{m}$. For a given injection pressure, the needle ceases to affect the ROI once lifted past this "full lift" point, from where the orifices take over fuel flow control. Note that overshoots of both needle lift and ROI are observed in the plot, especially for low-lift scenarios where the overshoots were largest. The steady state trends found in this study are similar to those estimated 

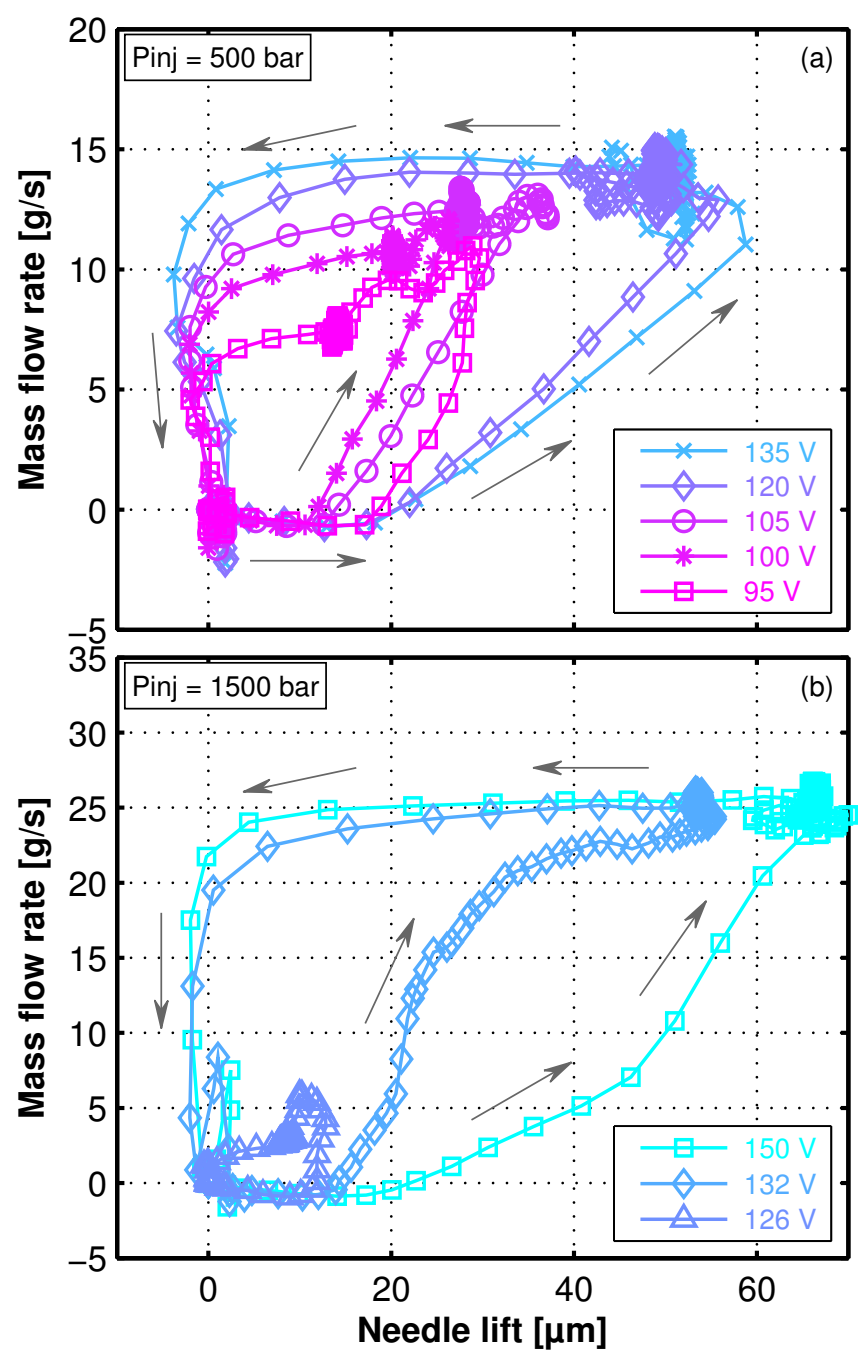

Figure 15: Instantaneous relationship between the ROI and needle lift. The light-gray arrows indicate the time evolution of the complete injection event, which goes anti-clockwise, from zero ROI and lift, to the steady state clouds of points corresponding to each test condition, and back. 
by Payri et al. [15], but to the authors' knowledge this is the first time this result is presented purely from experiments, and also the first time that the instantaneous link between needle lift and ROI has been analyzed.

Figure 15 provides interesting information regarding transients. Note that the needle opening initially causes a negative ROI - usually seen in instantaneous ROI measurements, as Figures 4, 5, and 6 show-due to the volume suddenly displaced in the nozzle sac. The opposite can be observed during the needle closing, where the sac volume is rapidly decreasing and therefore, fuel is pumped out even though the needle seat is being ever more restricted. This is the effect of rapid needle velocities and also occurs because the injection rate meter is filled with fuel. Thus, if the needle lift velocity is slower, the volume displacement effect should be decreased. At a rail pressure of 1500 bar, a control signal voltage of $132 \mathrm{~V}$ produced a slower needle lift velocity, as shown in Figure 12. Slower needle lift velocities are evidenced in Figure 15-(b) as points going from zero to the steady state condition through the center of the plot, almost following the expected trend of steady state ROI vs. needle lift. This suggests that producing injections with even slower needle lift velocities - which was possible but not thought to be of interest at the time of test planning - would render the full span of points for the link between quasi-steady needle lifts and ROIs. Note that these observations in the transient stages imply that there will always be a hydraulic delay in the steady ROI with respect to the reference energizing signal, even for direct-acting injectors.

\section{Conclusions}

In this study, experiments were carried out to measure both instantaneous rate of injection and needle lift for a prototype direct-acting injector capable of consistently producing injections with partial needle lifts. A series of test conditions and configurations were evaluated and their effects analyzed, and from these analyses the following conclusions can be drawn:

- The direct-acting injector is able to consistently throttle rates of injection by partially lifting the needle. The spectrum of possible throttling levels depended strongly on injection pressure - higher rail pressures reduce the throttling capabilities considerably. Pressure-induced distortions of the injector rocker mechanism appeared to limit needle lift control at high injection pressures. Two control signal rising ramp 
rates were evaluated, showing that they can indeed help in these lowlift limit situations. In general, partial needle lifts were able to decrease the discharge coefficient from approximately 0.81 to as low as 0.11 .

- The direct-acting feature of the injector can be utilized to consistently shape the injection rate signal as desired. Two 'boot' shaped rate of injection profiles were presented. The 'boot' shaped ROI signals were similar in consistency when compared to the conventional 'square' shaped ROI signals.

- The needle lift response - and with it, the rate of injection responsewas found to be of second order. The control signals were purposely maintained simple and square shaped to generate this behavior that, for low lift situations, produced a needle lift and thus, rate of injection overshoots in the initial stage of the injection event.

- The relationship between steady rate of injection and control signal voltage was found to be non-linear, while the relationship between steady needle lift and control signal voltage was found to be linear (except when rocker deformation interfered with needle lift).

- The rate of injection is affected by needle lift only up to a certain point. This point is dependent on injection pressure: at an injection pressure of 500 bar, the needle had to be lifted to approximately $50 \mu \mathrm{m}$ for it to cease throttling the rate of injection, while at 1500 bar it needed to be lifted to approximately $70 \mu \mathrm{m}$ for the same purpose.

- Fast needle movements displace volume in the sac, which alters the instantaneous rate of injection. This implies that there will always be a hydraulic delay between the control signal stabilization and the rate of injection, even for direct-acting injectors. The opening effect is expected to be reduced when injecting into a gas ambient.

Finally, the authors believe that it would be illuminating to study these results through multi-phase numerical models, and with them, to further evaluate the effects of needle lift and needle velocity over the instantaneous rate of injection and cavitation regimes in the needle seat. This may provide detailed insights into the physical processes that drive these observations, and potentially, to the effects that these features could have on combustion performance. 


\section{Acknowledgements}

This research was performed at the 32-ID beam line of the APS at Argonne National Laboratory. Use of the APS is supported by the U.S. Department of Energy (DOE) under Contract No. DE-AC02-06CH11357. The fuel spray research is sponsored by the DOE Vehicle Technologies Program. The authors wish to thank Gurpreet Singh and Leo Broten for their support of this work. Raul Payri was funded by a Fulbright visiting scholar grant in collaboration with the Ministry of Education, Culture and Sports of Spain (reference PRX14/00331) while performing this work. J.P. Viera was funded by the Spanish MINECO grant EEBB-I-15-0976 under project TRA2012-36932.

The submitted manuscript has been created by UChicago Argonne, LLC, Operator of Argonne National Laboratory (Argonne). Argonne, a U.S. Department of Energy Office of Science laboratory, is operated under Contract No. DE-AC02-06CH11357. The U.S. Government retains for itself, and others acting on its behalf, a paid-up nonexclusive, irrevocable worldwide license in said article to reproduce, prepare derivative works, distribute copies to the public, and perform publicly and display publicly, by or on behalf of the Government.

\section{References}

[1] S. Soid, Z. Zainal, Spray and combustion characterization for internal combustion engines using optical measuring techniques - A review, Energy 36 (2) (2011) 724 - 741, ISSN 0360-5442, doi: http://dx.doi.org/10.1016/j.energy.2010.11.022.

[2] F. Wang, Z. He, J. Liu, Q. Wang, Diesel nozzle geometries on spray characteristics with a spray model coupled with nozzle cavitating flow, International Journal of Automotive Technology 16 (4) (2015) 539 - 549, ISSN 1229-9138, doi:10.1007/s12239-015-0055-9.

[3] R. Payri, F. J. Salvador, J. Gimeno, J. de la Morena, Influence of injector technology on injection and combustion development - Part 1: Hydraulic characterization, Applied Energy 88 (4) (2011) 1068 - 1074, ISSN 03062619, doi:http://dx.doi.org/10.1016/j.apenergy.2010.10.012.

[4] R. Payri, F. J. Salvador, J. Gimeno, J. de la Morena, Influence of injector technology on injection and combustion development - Part 2: 
Combustion analysis, Applied Energy 88 (4) (2011) 1130 - 1139, ISSN 0306-2619, doi:http://dx.doi.org/10.1016/j.apenergy.2010.10.004.

[5] R. Mobasheri, Z. Peng, S. M. Mirsalim, Analysis the effect of advanced injection strategies on engine performance and pollutant emissions in a heavy duty DI-diesel engine by CFD modeling, International Journal of Heat and Fluid Flow 33 (1) (2012) 59 - 69, ISSN 0142-727X, doi: http://dx.doi.org/10.1016/j.ijheatfluidflow.2011.10.004.

[6] J. Benajes, S. Molina, A. García, J. Monsalve-Serrano, Effects of direct injection timing and blending ratio on RCCI combustion with different low reactivity fuels, Energy Conversion and Management 99 (2015) 193 - 209, ISSN 0196-8904, doi: http://dx.doi.org/10.1016/j.enconman.2015.04.046.

[7] P. Das, P. Subbarao, J. Subrahmanyam, Effect of main injection timing for controlling the combustion phasing of a homogeneous charge compression ignition engine using a new dual injection strategy, Energy Conversion and Management 95 (2015) 248 - 258, ISSN 0196-8904, doi:http://dx.doi.org/10.1016/j.enconman.2015.02.018.

[8] D. Schöppe, S. Zülch, M. Hardy, D. Geurts, R. W. Jorach, N. Baker, Delphi Common Rail system with direct acting injector, MTZ Worldwide 69 (10) (2008) 32 - 38, doi:10.1007/BF03226918.

[9] G. Dober, S. Tullis, G. Greeves, N. Milovanovic, M. Hardy, S. Zuelch, The impact of injection strategies on emissions reduction and power output of future diesel engines, SAE Technical Paper 2008-01-0941, doi: 10.4271/2008-01-0941.

[10] F. Atzler, O. Kastner, R. Rotondi, A. Weigand, Multiple injection and rate shaping Part 1: Emissions reduction in passenger car diesel engines, SAE Technical Paper 2009-24-0004, doi:10.4271/2009-24-0004, URL http://dx.doi .org/10.4271/2009-24-0004.

[11] G. Dober, N. Guerrassi, K. Karimi, Mixture preparation and combustion analysis, a key activity for future trends in diesel fuel injection equipment, in: SIA, Rouen, France, 2012. 
[12] O. Chiavola, F. Palmieri, Modeling needle motion influence on nozzle flow in high pressure Injection System, SAE Technical Paper 2007-010250, doi:10.4271/2007-01-0250.

[13] S. Som, S. K. Aggarwal, E. M. El-Hannouny, D. E. Longman, Investigation of nozzle flow and cavitation characteristics in a diesel injector., Journal of Engineering for Gas Turbines and Power 132 (4) (2010) 042802, doi:doi:10.1115/1.3203146.

[14] A. Ferrari, A. Mittica, FEM modeling of the piezoelectric driving system in the design of direct-acting diesel injectors, Applied Energy 99 (2012) 471 - 483, ISSN 0306-2619, doi: http://dx.doi.org/10.1016/j.apenergy.2012.05.048.

[15] R. Payri, J. Gimeno, O. Venegas, A. H. Plazas, Experimental and computational study of the influence of partial needle lift on nozzle flow in diesel fuel injectors, Atomization and Sprays 22 (8) (2012) 687 - 714, ISSN 1044-5110, doi:10.1615/AtomizSpr.2012005810.

[16] R. Payri, J. Gimeno, M. Bardi, A. H. Plazas, Study liquid length penetration results obtained with a direct acting piezo electric injector, Applied Energy 106 (2013) 152 - 162, ISSN 0306-2619, doi: http://dx.doi.org/10.1016/j.apenergy.2013.01.027.

[17] R. Payri, J. Gimeno, J. P. Viera, A. H. Plazas, Needle lift profile influence on the vapor phase penetration for a prototype diesel direct acting piezoelectric injector, Fuel 113 (2013) 257 - 265, ISSN 0016-2361, doi: http://dx.doi.org/10.1016/j.fuel.2013.05.057.

[18] J. M. Desantes, F. J. Salvador, M. Carreres, J. Martínez-López, Largeeddy simulation analysis of the influence of the needle lift on the cavitation in diesel injector nozzles, Proceedings of the Institution of Mechanical Engineers, Part D: Journal of Automobile Engineering 229 (4) (2015) 407-423.

[19] W. Lee, K. Fezzaa, J. Wang, Metrology of steel micronozzles using xray propagation-based phase-enhanced microimaging, Applied Physics Letters 87 (8) (2005) 084105.

[20] A. L. Kastengren, F. Z. Tilocco, C. Powell, J. Manin, L. M. Pickett, R. Payri, T. Bazyn, Engine Combustion Network (ECN): measurements 
of nozzle geometry and hydraulic behavior, Atomization and Sprays 22 (12) (2012) 1011-1052.

[21] A. Kastengren, C. Powell, F. Tilocco, Z. Liu, S. Moon, X. Zhang, J. Gao, Correlation of split-injection needle lift and spray structure, SAE Technical Paper 2011-01-0383.

[22] C. Powell, A. L. Kastengren, Z. Liu, K. Fezzaa, The effects of diesel injector needle motion on spray structure, Journal of Engineering for Gas Turbines and Power 133 (1) (2011) 012802.

[23] D. J. Duke, A. Swantek, Z. Tilocco, A. Kastengren, K. Fezzaa, K. Neroorkar, M. Moulai, C. Powell, D. Schmidt, X-ray imaging of cavitation in diesel injectors, SAE Int. J. Engines 7 (2) (2014) 1003-1016, doi:10.4271/2014-01-1404.

[24] W. Bosch, The fuel rate indicator: a new measuring instrument for display of the characteristics of individual injection, SAE Technical Paper 660749, doi:10.4271/660749.

[25] R. Payri, F. J. Salvador, J. Gimeno, G. Bracho, A new methodology for correcting the signal cumulative phenomenon on injection rate measurements, Experimental Techniques 32 (1) (2008) 46-49, ISSN 1747-1567, doi:10.1111/j.1747-1567.2007.00188.x.

[26] R. Payri, J. M. García, F. J. Salvador, J. Gimeno, Using spray momentum flux measurements to understand the influence of diesel nozzle geometry on spray characteristics, Fuel 84 (5) (2005) 551 - 561, ISSN 0016-2361, doi:http://dx.doi.org/10.1016/j.fuel.2004.10.009.

[27] Q. Shen, W. Lee, K. Fezzaa, Y. S. Chu, F. De Carlo, P. Jemian, J. Ilavsky, M. Erdmann, G. G. Long, Dedicated full-field X-ray imaging beamline at Advanced Photon Source, Nuclear instruments and methods in physics research section A 582 (1) (2007) 77-79.

[28] J. A. Mares, A. Beitlerova, M. Nikl, N. Solovieva, C. D'Ambrosio, K. Blazek, P. Maly, K. Nejezchleb, F. de Notaristefani, Scintillation response of Ce-doped or intrinsic scintillating crystals in the range up to, Radiation Measurements 38 (4-6) (2004) 353-357, doi: 10.1016/j.radmeas.2004.04.004. 